\title{
FATORES DE RISCOS ASSOCIADOS À LEPTOSPIROSE EM EQUÍDEOS: REVISÃO DE LITERATURA
}

\author{
Paulo Acioli ALVES PINTO; ;osé Andreey Almeida TELES²; Gil Dutra FURTADO*
}

\author{
${ }^{1}$ Graduação em Medicina Veterinária/Centro Universitário Cesmac, Marechal Deodoro, Alagoas; Especialista \\ em Reprodução e clínica Médica de Equinos e Bovinos/QUALITTAS Instituto de Pós-Graduação, Campinas, \\ São Paulo, Brasil. \\ ${ }^{2}$ Mestre em Biociência Animal, Médico Veterinário, Professor/Centro Universitário Maurício de Nassau \\ (UNINASSAU-PB), João Pessoa, Paraíba, Brasil. \\ ${ }^{3}$ Graduando em Medicina Veterinária/UNINASSAU-PB, João Pessoa, Paraíba; Agrônomo/Universidade Federal \\ da Paraíba (UFPB); Doutor em Psicobiologia/Universidade Federal do Rio Grande do Norte (UFRN); \\ Agrônomo-Sócio da Cooperativa do Agronegócio (COOPAGRO), Natal, Rio Grande do Norte, Brasil. \\ *Autor para correspondência. E-mail: gdfurtado@hotmail.com
}

Resumo. A leptospirose é uma doença de distribuição cosmopolita, que apresenta incidência significativa, sendo, portanto, mais comum em países tropicais de clima quente e úmido. A doença é uma antropozoonose direta que acomete humanos, animais domésticos e selvagens. O gênero Leptospira é formado por espiroquetas que pertencem a ordem Spirochaetales, família Leptospiraceae são consideradas bactérias patogênicas, aeróbias obrigatórias, espiraladas, flexíveis e móveis. Nos equídeos, a leptospirose pode apresentar sintomatologia reprodutiva, ocular e respiratória, porém muitas vezes os animais são assintomáticos. Através de dados epidemiológicos e pela sintomatologia clínica, associando tais fatores aos testes laboratoriais, se pode chegar ao diagnóstico dessa enfermidade. Não existe um protocolo fixo para o tratamento da leptospirose em equídeos, porém, existe um consenso entre os clínicos e pesquisadores a respeito da utilização de antibióticos. $\mathrm{O}$ objetivo do trabalho foi realizar uma revisão de literatura, enfatizando os fatores de riscos associados a leptospirose em equídeos.

Palavras-chave: Leptospirose; Equídeos; Antropozoonose.

\section{RISK FACTORS ASSOCIATED WITH LEPTOSPIROSIS IN EQUIDES: LITERATURE REVIEW}

Abstract. Leptospirosis is a disease cosmopolitan distribution, which has a significant impact, and is therefore more common in tropical countries with hot and humid weather. The disease is a direct anthropozoonosis that affects humans, domestic and wild. The genus Leptospira is formed by spirochetes belonging to the order Spirochaetales, family Leptospiraceae are considered pathogenic bacteria, aerobic binding, spiral, flexible and mobile. In equine leptospirosis can present symptoms 
reproductive, ocular, respiratory, but animals are often asymptomatic. Through epidemiological data and the clinical symptoms, linking such factors to laboratory tests, it can make the diagnosis of this disease. There is no fixed protocol for the treatment of leptospirosis in horses, however, there is a consensus among clinicians and researchers about the use of antibiotics. The objective was to conduct a literature review, emphasizing the risk factors associated with leptospirosis in horses.

Keywords: Leptospirosis; Equidae; Anthropozoonosis.

\section{FACTORES DE RIESGO ASOCIADOS A LEPTOSPIROSIS EN EQUIDOS: REVISIÓN DE LITERATURA}

Resumen. La leptospirosis es una distribución cosmopolita de la enfermedad, que tiene un impacto significativo y, por lo tanto, es más común en países tropicales con clima cálido y húmedo. La enfermedad es una antropozoonosis directa que afecta a humanos, domésticos y salvajes. El género Leptospira está formado por espiroquetas que pertenecen al orden Spirochaetales, la familia Leptospiraceae se consideran bacterias patógenas, de unión aeróbica, espiral, flexible y móvil. En la leptospirosis equina pueden presentarse síntomas reproductivos, oculares, respiratorios, pero los animales a menudo son asintomáticos. A través de los datos epidemiológicos y los síntomas clínicos, que vinculan dichos factores con las pruebas de laboratorio, puede hacer el diagnóstico de esta enfermedad. No existe un protocolo fijo para el tratamiento de la leptospirosis en caballos, sin embargo, existe un consenso entre médicos e investigadores sobre el uso de antibióticos. El objetivo fue realizar una revisión de la literatura, enfatizando los factores de riesgo asociados con la leptospirosis en caballos.

Palabras clave: Leptospirosis; Équidos; Antropozoonosis.

\section{INTRODUÇÃO}

De acordo com dados do Ministério da Agricultura Pecuária e Abastecimento - MAPA, a população de equídeos no Brasil é considerada a maior da América Latina e a terceira do mundo, totalizando aproximadamente 8 milhões de cabeças quando somados a população de muares e asininos. A maior parte dos equinos encontra-se na região Sudeste, seguida pelas regiões do Nordeste, Centro Oeste, Sul e Norte, gerando assim, uma movimentação de 7,3 bilhões de reais anuais, distribuídos entre insumos, criação e destinação final, compondo-se a base do complexo do agronegócio do cavalo, no qual é responsável pela geração de 3,2 milhões de empregos sejam eles, diretos ou indiretos (MAPA, 2016).

Os equinos foram utilizados durante vários anos unicamente como meio de transporte, porém, tem conquistado outras áreas de atuação como lazer, esporte e terapia. No 
tocante à exportação de cavalos vivos, a expansão alcançou 524\% entre 1997 e 2009. O Brasil é o oitavo maior exportador de carne de equinos do mundo, sendo a Bélgica, Holanda, Itália, Japão, França e os Estados Unidos são os principais importadores da carne equina brasileira (MAPA, 2016).

O manejo sanitário é um conjunto de procedimentos que quando devidamente aplicados em qualquer sistema de criação independentemente de se tratar de animais de produção ou não, proporcionam aos animais ótimas condições de saúde, além de contribuir com a prevenção de doenças e na minimização de fatores de risco e, ainda de aumentar a produção e produtividade (DOMINGUES; LANGONI, 2001).

A leptospirose é uma doença de distribuição cosmopolita, que apresenta incidência significativa, sendo, portanto, mais comum em países tropicais de clima quente e úmido (LEVETT, 2001). Essa doença já foi diagnosticada em todos os continentes, entretanto, na América Latina, África e Ásia, elevados índices de ocorrência são encontrados, devido às condições ambientais se mostrarem favoráveis à persistência e à disseminação do agente (BLENDEN, 1976). A doença é uma antropozoonose direta que acomete humanos, animais domésticos e selvagens, sendo causada por diversos sorovares (svs) patogênicos dentro do gênero Leptospira, os quais podem estar presentes na água, solo e reservatórios animais (FAINE, 2000).

As leptospiras são bactérias patogênicas, aeróbias obrigatórias, espiraladas, flexíveis e móveis, que podem ser visualizadas através de microscópio de campo escuro ou de contraste de fase e se coram por corantes argênicos (BEER, 1988; VERONESI, 1991; PARMA et al., 1997; VASCONCELLOS, 1997).

No Brasil têm sido desenvolvidos trabalhos sucessivos voltados à espécie equina, os quais têm reportado como mais frequentes os svs: Icterohaemorragiae, Pomona, Wolffi, Hardjo, Canicola, Australis, Autumnalis, Ballum, Batavie, Grippotyphosa, Javanica, Panama, Pyrogenes, Tarassovi, Castelloni, Hebdomadis, Sejröe, Bratislava e Butemb (FREITAS et al., 1960; JARDIM et al., 1978; ABUCHAIM, 1991; ARAÚJO et al., 2001; MOLNAR et al., 2001).

Nos equinos, a leptospirose foi descrita de forma subclínica, resultando em abortamentos, nascimentos de animais prematuros e debilitados. Sendo que nessa espécie os sintomas mais frequentes são febre, icterícia, nefrite e complicações oculares (HONG et al., 1993), sendo que a oftalmia se instala após a fase de latência da doença, podendo ser detectada pela presença de leptospiras nas lesões oculares e alta concentração de anticorpos 
no humor aquoso (RADOSTITS et al., 2000); constatando-se assim, grande prejuízo econômico no setor do agronegócio do cavalo, seja por perdas diretas ou indiretas tais quais gastos com tratamento, baixa produtividade animal, abortamentos, natimortalidade, desvalorização do animal, queda de performance atlética e até mesmo por morte (GILGER, 2003).

\section{REVISÃO DE LITERATURA}

\section{Aspectos gerais e histórico da leptospirose}

No ano de 1881 foi descrito pelo Dr. Weiss em Praga, uma enfermidade que posteriormente seria conhecida como leptospirose. O primeiro relato oficial da doença foi realizado por Adolf Weil no ano de 1886 na Alemanha. Em 1907, através da realização de uma necropsia, foram isolados esses microorganismos oriundos de um rim. Inada e Ido identificaram a bactéria no ano de 1915 no Japão. Nesse mesmo período, Uhlenhut e Fromme, confirmaram a presença da leptospira através da inoculação de sangue em cobaias, oriundos de soldados que se apresentavam suspeitos para a doença, após a inoculação os animais inoculados morreram com a mesma doença dos soldados (AMORIM; FERREIRA, 2009).

Na Rússia em 1947 foi publicado o primeiro caso de Leptospirose em equinos. Já na América do Norte, a doença tem sido relatada desde 1952, com casos de abortamento, ocorrência de natimortos, disfunção hepática e renal, além de oftalmia periódica (LEES e GALE, 1994). Existem evidências de que, há mais de 60 anos, a infecção por leptospiras tenha sido caracterizada pela identificação de aglutininas específicas anti-leptospiras, em equinos em alguns estados do Brasil (CORRÊA et al., 1957).

Em um trabalho realizado por Giorgio et al., no ano de 1981, se deu o primeiro diagnóstico de leptospirose em equinos no Brasil, através do isolamento da $L$. icterohaemorrhagiae a partir de feto abortado (PESCADOR et al., 2004).

De acordo com o Subcomitê em Taxonomia de Leptospira, em 1992 foi proposta a divisão da Leptospira interrogans em sete espécies (QUINN et al., 1994), porém em reunião realizada no Equador no ano de 2007 essa divisão foi reclassificada em 13 espécies patogênicas de Leptospiras: L. alexanderi, L. alstonii, L. borgpetersenii, L. inadai, L. interrogans, L. fainei, L. kirschneri, L. licerasiae, L. noguchi, L. santarosai, L. terpstrae, L. weilii e $L$. wolffii onde as quais foram distribuídas em mais de 260 sorovariedades agrupadas em 23 sorogrupos (MELO et al., 2010). As L. biflexa, L. wolbachii e L. hollandia fazem parte 
das espécies saprófitas, ou seja, de vida livre, no qual possuem 38 svs agrupados em seis sorogrupos, encontrada preferencialmente em água doce (PEREIRA, 2009; SANTANA, 2008).

\section{Etiologia}

A denominação do gênero Leptospira vem do grego, que significa Lepto = fino, pequeno, delicado e speira = espiral, (LEVETT, 2001). São consideradas bactérias patogênicas pertencentes a ordem Spirochaetales, família Leptospiracae e espiroquetas do gênero Leptospira. O gênero Leptospira inicialmente foi dividido em duas espécies: L. biflexa e $L$. interrogans, cada uma dividida em várias sorovariedades, que são as de vida livre consideradas como saprófitas (L. biflexa), e os responsáveis pela infecção nos animais domésticos e no homem (L. interrogans), ou seja, patogênicas. (SCHMIDT et al., 2002; PEREIRA, 2009; MELO et al., 2010).

As bactérias do gênero Leptospira são helicoidais com comprimento de $6 \mu \mathrm{m}$ a $20 \mu \mathrm{m}$ por aproximadamente $0,1 \mu \mathrm{m}$ de diâmetro, multiplicam-se por divisão binária, são aeróbias obrigatórias e móveis, com ganchos terminais característicos em uma ou ambas as extremidades, porém em condições adversas podem ser alongados, em tecidos ou culturas recentes com alta concentração de sal podem ter uma forma cocóide (ELLIS, 1994; FAINE et al., 2000).

Desenvolvem-se em temperatura ótima de $28^{\circ} \mathrm{C}$ a $30^{\circ} \mathrm{C}$ e $\mathrm{pH}$ de 7,2 a 7,6 (FAINE et al., 2000), porém por terem requerimentos nutricionais elevados, demandam meios especiais de cultivo, não crescendo na ausência de albumina ou soro, sendo assim necessários meios enriquecidos com albumina bovina sérica (BSA), soro de coelho, vitamina B1 e B12, amônia e ferro (FAINE et al., 2000; LEVETT, 2001).

\section{Epidemiologia}

A leptospirose é uma antropozoonose de distribuição mundial, caracterizada como uma doença epidêmica apresentando-se com maior frequência em épocas chuvosas e inundações urbanas, considerada assim como doença sazonal (GUIDUGLI, 2006). Essa enfermidade pode acometer animais silvestres, domésticos e o homem, representando assim, um importante problema seja ele de caráter econômico e principalmente no tocante a saúde pública (BARWICK et al., 1997; BHARTI et al., 2003). 
Segundo Thomassian (2005) na espécie equina os sorotipos mais importantes são Icterohaemorrhagiae, Pomona, Hardjo e Canicola, podendo assim ser transmitidos por portadores que podem contaminar água, solo e alimentos, porém Pinna et al (2007) relatam que a doença, apesar de ter ocorrência mundial, com destaque predominante para o sorovar (sv) L. interrogans, a presença deste pode variar em diferentes países. Entretanto, a prevalência de infecção por leptospira em equinos pelos svs Icterohaemorrhagiae ou Pomona é bem documentada enquanto o sv Bratislava é menos frequentemente citado.

Radostits et al., 2002, descreve que os svs Kennewicki e Pomona são os mais comumente encontrados como agentes causadores de abortamento em equinos, apesar dos svs Bratislava, Icterohaemorrhagie, Grippotyphosa, Hardjo e Canicola já terem sido reportados. Segundo Favero et al (2002) e Langoni et al (2004), no Brasil existem variações de svs em equinos, todavia são encontrados com maior frequência os svs Pomona, Icterohaemorrhagiae, Pirogenes e Bratislava.

Yan et al. 2010 descreveram um estudo com infecção experimental por Leptospira interrogans sv Kinnewicki e demonstrou que os cavalos apresentaram leptospiremia de 2 a 6 dias e leptospirúria 4 semanas após a infecção, comprovando, com isso, que os cavalos podem ser disseminadores da leptospirose.

No Brasil, o sv Brastilava apesar de nunca ter sido isolado nem tipificado, evidências sorológicas da presença do mesmo foram relatadas nos estados de São Paulo (LANGONI et al., 2004) e do Rio de Janeiro, mas a correlação com os casos clínicos, ainda não é muito bem conhecida (LILENBAUM, 1998; PINNA et al., 2007).

Os roedores domésticos (Rattus norvegicus, Rattus rattus e Mus musculus) são os principais reservatórios do agente e apresentam normalmente em seus túbulos renais a bactéria Leptospira, tornando-se assim largamente distribuída no ambiente, no qual são excretadas através da urina por vários meses, contaminando solo, água e alimentos. As Leptospiras necessitam de condições especiais como clima temperado e úmido, solos saturados de água e pH próximo da neutralidade $(7,2$ - 7,6) para sua persistência no ambiente, tornando-se assim viável, a sobrevivência das mesmas, por um período de 180 dias, além de sobreviverem ao frio e até mesmo ao congelamento, porém o agente é sensível a desinfetantes comuns, luz solar direta, dessecação, variação de pH porém só resistem 30 minutos quando o ar e solo estão secos (FARIAS, 1999; RADOSTITIS et al., 2000; QUINN et al., 2005; RIETCORREA et al., 2007). 
As bactérias do gênero Leptospira não apresentam boa resistência, sendo muito sensíveis ao ressecamento, desinfetantes, temperaturas elevadas $\left(50^{\circ} \mathrm{C}\right.$ a $\left.60^{\circ} \mathrm{C}\right)$ e a oscilações de pH (FAINE, 2000), porém quando na água e em culturas, sobrevivem por longos períodos (TRUEBA et al., 2004) assim como em solos, lama, água doce acumulada e rios (NELSON; COUTO, 2006). As espécies patogênicas podem sobreviver no ambiente, porém, preferencialmente, encontra-se no hospedeiro, onde se multiplicam (FAINE, 2000), já as espécies saprófitas sobrevivem e se multiplicam na água e no solo (PICARDEAU et al., 2008).

Os equinos após ingerirem água, alimentos, ou permanecerem em locais contendo Leptospira spp. oriundos de excretas de animais infectados, podem contrair a doença (PAVORD; PAVORD, 2007), uma vez que, as vias clássicas da infecção por leptospirose são através do contato da bactéria com a pele lesada ou mucosa e até mesmo com a pele íntegra (LEVET, 2001; QUINN et al., 2005), podendo também ser transmitida através do sêmen e por via transplacentária (BOLIN; PRESCOTT, 1999).

Os reservatórios ou hospedeiros de manutenção das Leptospiras são bastante variados, onde o sv de predileção de uma determinada espécie se adapta a outra espécie animal e estes, por sua vez, podem ser hospedeiros acidentais de outros svs, causando a forma aguda da doença (FAINE et al., 2000).

Corrêa et al., 1957, realizou a primeira pesquisa no Brasil, no estado de São Paulo, abordando a infecção por Leptospiras em equinos. Foram analisadas 118 amostras sorológicas através do teste de Soroaglutinação Microscópica (SAM), onde foi constatado $16,9 \%$ de animais positivos, dos quais se destacou os svs Australis, Icterohaemorrhagiae e Serjroe.

Em pesquisa realizada por Romero et al., 1994, em fazendas pertencentes ao Instituto Butantã em São Roque - São Paulo, utilizando o SAM para avaliar 922 soros, a fim de comprovar a positividade da L. interrogans utilizando 23 svs distintos, 753 (81,7\%) espécimes apresentaram-se positivos com títulos variando de 100 a 6400, e apenas o sv Tarassovi não foi identificado, porém os que apresentaram maior frequência foram os svs Icterohaemorragiae (73,3\%), seguido do Autumnalis (28,7\%), Brasiliensis (23\%), Copenhageni (19,8\%) e, por fim o Pyrogenes (18,9\%).

Em trabalho realizado por Langoni et al (2004), nos estados de São Paulo, Mato Grosso do Sul e Goiás, foram avaliados 1402 equinos destinados a esporte e trabalho, destes 754 (54\%), apresentaram-se positivos para Leptospira, com maior predominância para o sv Icterohaemorragiae o que foi representado por 520 (37\%) amostras. Essa predominância é 
sugerida pelo autor pelo fato da presença de roedores que partilham ambientes com os equinos.

Foram analisados pelo SAM, 420 espécimes obtidos de equinos provenientes de nove municípios do Rio Grande do Sul, dos quais 37,4\% apresentaram titulação igual ou superior a 100, sendo assim considerados reagentes, destacando-se os svs Icterohaemorragiae e Pomona, destes 55,6\% não apresentavam sinais clínicos para a doença (ABUCHAIM, 1991).

Em trabalho realizado por Pires Neto (2005) no município de Eldorado do Sul - RS no período de 2000 a 2003 foram analisadas 1169 amostras sorológicas de equinos, das quais $871(74,5 \%)$ tiveram resultado positivo para Leptospira, predominando svs Bratislava 174 (19,92\%), seguido do Copenhageni 131 (15,06\%), L. pyrogenes 89 (10,19\%), L. hardjo 88 (10, 13\%), L. australis 84 (9,63\%), L. icterohaemorrhagiae 56 (6,47\%), L. autumnalis 54 (6,24\%), L. tarassovi 54 (6,20\%), L. Pomona 48 (5,55\%), L. canicola 38 (4,39\%), L. wolffi 25 (2,85\%), L. grippotyphosa 20 (2,20\%) e L. hebdomadis 10 (1,08\%). O mesmo autor sugeriu que a predominância do sv Bratislava deve-se por ele ser bastante adaptado ao cavalo, o que explica a alta prevalência.

Pinna et al (2007), em estudo realizado na região serrana do Rio de Janeiro com 148 equinos (140 éguas e 08 garanhões), identificaram $82(55,4 \%)$ positivos no tocante à presença de Leptospira. Sendo identificados como causadores os svs Batislava em 72 animais (87,8\%), Icterohaemorragiae em 06 (7,3\%) e Australis como agente etiológico de 04 (4,9\%). Mesmo sabendo-se que os svs mais frequentes associados a sinais clínicos agudos e de ocorrência de leptospirose em equinos sejam os sorovares Pomona e Icterohaemorrhagiae, a presença de outros svs, a exemplo do Bratislava, pode ser justificada através do ingresso de animais oriundos de diferentes haras localizados em diversas regiões do país.

Ainda segundo Pinna et al (2007), os fatores que contribuem para o alastramento de svs entre regiões distintas do país é a ausência de comprovação de soronegatividade para leptospirose e a não realização de quarentena em animais recém-adquiridos. Tal fato pode estar ainda associado às características ambientais dos locais de origem, como áreas alagadas e lago para exercícios, permitindo assim a disseminação e manutenção desses sorovares, uma vez que nas propriedades que adquiriram os animais foi realizado um eficiente controle de roedores, por serem estes reservatórios naturais do sv Icterohaemorrahagiae, na perspectiva de reduzir o aparecimento do mesmo. 
Durante o período de 2004 a 2005 foram analisados 39 cavalos de carroça, oriundos da cidade de Santa Maria - RS, a fim de avaliar a presença de Leptospiras através do método SAM. Todos os animais apresentaram se positivos ao teste, encontrando-se assim os svs Icterhaemorrhagiae (19,85\%), Bratislava (17,65\%), Butembo (12,50\%), Australis (10,29\%), Copenhageni (8,09\%), Pyrogenes (7,35\%), Hardjo (5,88\%), Castellonis (5,15\%), Pomona (5,15\%), Autumnalis $(4,41 \%)$ e Canicola (3,68\%) (Maciel et al., 2008). De acordo com Barcellos et al., 2003, a predominância do serovar Icterohemorrhagiae pode estar relacionada ao fato de que os equinos de carroceiros habitam geralmente lugares perto ou no próprio depósito de material reciclável, fato este que oportuniza a presença de roedores os quais são considerados como reservatório desse sorovar.

Em trabalho realizado em São Luís do Maranhão a fim de averiguar a presença de leptospirose através do método SAM, utilizou-se 30 sorotipos diferentes, onde o total de amostras testadas foram 120, sendo 60 amostras de asininos e 60 dos condutores de carroça. Dos 60 asininos testados obteve-se (85\%) de soro-reatividade para um ou mais sorovares com reação em $(70 \%)$ sorovares diferentes, nos quais predominaram os sorotipos Copenhageni (25,75\%), Pyrogenes (21,97\%), Atumnalis (13,66\%) e Icterohaemorrhagiae (8,33\%). Com relação aos condutores, $38,4 \%$ apresentaram-se positivos, sendo com mais frequência para os sorovares Copenhageni (23,33\%), Pyrogenes (20\%) e Icterohaemorrhagiae (16,67\%). Diante desses resultados o autor acredita que ambas as espécies estavam expostas às mesmas fontes de infecção, onde as condições ambientais eram favoráveis à disseminação (ARAÚJO et al., 2001)

Em trabalho realizado por dos Santos, et al (2012) na microrregião de Itaguaí - RJ foram coletadas 139 amostras de soro sanguíneo, sendo 03 de jumentos da raça pêga, 04 de muares e 132 de equinos, a fim de averiguar a soreatividade quanto à presença de Leptospiras a partir de 24 svs diferentes, por meio do teste SAM. Do total de amostras avaliadas, 100 $(71,9 \%)$ reagiram, das quais $33(33 \%)$ tiveram reação a apenas um sv e 67 (67\%) foram reagentes a dois ou mais svs, obtendo-se assim positividade para 10 svs distintos. Dos svs encontrados os mais frequentes em ordem decrescente foram Bratislava 62 (62\%) amostras, seguido do Pomona 42 (42\%), Copenhageni 37 (37\%), Hardjoprajitno 27 (27\%), Castellonis $13(13 \%)$ e Pyrogenes $11(11 \%)$.

Ainda de acordo com dos Santos et al (2012), na região estudada os equinos têm contato com outros animais no mesmo pasto como bovinos e suínos, além da presença de cães e animais silvestres como gambás e gatos do mato. Segundo Ellis (1983) a alta prevalência do 
sorovar Bratislava em equinos com problemas reprodutores é sugerida pelo fato de o hospedeiro estar adaptado a esse sorovar.

Em estudo realizado através do teste SAM, frente a 18 svs distintos de Leptospira para identificação de leptospirose em 106 éguas oriundas do município de Itagibá - BA, todas possuíam histórico de abortamento, salientando que em algumas amostras houve reação positiva para mais de um sv. Na ocasião foi obtido o seguinte resultado: 24 espécimes (23\%) foram reagentes, dessas, 17 (42\%) apresentaram-se positivas para o sv Icterohaemorrhagiae, $10(24 \%)$ para Pyrogenes, $07(17 \%)$ para Wolffi, $03(7 \%)$ para Castellonis e $03(7 \%)$ para Autumnalis. De acordo com Gomes et al (2007) a presença de aglutininas anti-leptospiras observadas pelo teste SAM foi conclusiva para o diagnóstico desses animais, e dá ênfase que a doença além de provocar perdas econômicas significativas representa um grande problema de saúde pública.

Em pesquisa com 150 equinos oriundos de propriedades do Pantanal, foi constatado positividade em todos os rebanhos, predominando assim os svs Icterohaemorrhagiae e Hardjo. De acordo com Pellegrin et al (1994) a prevalência do sv Hardjo nesse estudo foi sugerido pelo fato dos animais terem contato direto ou indireto com bovinos, uma vez que os mesmos são hospedeiros de manutenção desse sorotipo.

Foram submetidos ao teste SAM 182 soros de cavalos oriundos da microrregião de Goiânia - GO, a fim de pesquisar a prevalência da Leptospira Interrogans nesses animais diante de 16 svs distintos. Do total de espécimes submetidos ao exame, 82 (45,05\%) foram considerados positivos, desses, $56(68,29 \%)$ foram positivos para o sv Icterohaemorrhagie, 11 (13,41\%) Pomona, 07 (8,53\%) Wolffi, 05 (6,09\%) Hardjoe 03 (3,65\%) para tipo Canicola. De acordo com os pesquisadores, as divergências obtidas neste estudo se devem ao número e aos tipos de svs utilizados na avaliação sorológica, além de fatores como manejo higiênicosanitário dos rebanhos, grau e tipo de exposição a outros animais, sejam silvestres ou domésticos, inclusive os roedores (LINHARES et al., 2005).

Nos anos de 2003 e 2004 foi realizado trabalho para determinar a frequência e a distribuição espacial da infecção por Leptospira interrogans em 6475 equinos oriundos dos 853 municípios do estado de Minas Gerais através da técnica de microaglutinação rápida (MAR), onde os svs utilizados para o estudo foram Bratislava, Ballum, Batavie, Canicola, Copenhageni, Icterohaemorrhagiae, Pomona e Hardjo. Do total de amostras 381 (44,66\%) foram positivas para uma ou mais svs, considerando-se assim quando apresentaram com títulos 1:200. No referido estudo, os svs mais prevalentes foram Hardjo (3,0\%) e Pomona 
(1,2\%), seguidas de Bratislava (0,66\%), Batavie (0,53\%), Canicola (0,42\%), Icterohaemorrhagiae (0,42\%), Ballum (0,06\%) e Copenhageni $(0,02 \%)$. De acordo com alguns pesquisadores não era esperado que a Hardjo fosse o sv mais frequente uma vez que essa sorovariedade é comum na espécie bovina (ELLIS et al., 1981; ARAÚJO et al., 2005), porém o que justifica tal fato é que os equídeos em Minas Gerais são criados, na maioria das vezes, no mesmo habitat dos bovinos, e o contato direto ou indireto com estes últimos justificaria esse resultado, uma vez que os equídeos são hospedeiros acidentais (CHIARELLI et al., 2008).

Segundo Kinde et al (1996), para a espécie equina o sv Icterohaemorrhagiae é considerado o mais frequente e, portanto, sugere-se que 50\% dos rebanhos possam estar infectados com esse sv. Em alguns surtos a ocorrência da enfermidade está relacionada com as enchentes.

\section{Patogenia}

Os equinos adquirem a doença através da penetração das leptospiras pelas mucosas e pele intacta ou lesionada, disseminando-se assim por via hematógena. Uma vez na corrente sanguínea, o agente passa por um processo denominado leptospiremia (fase de multiplicação sistêmica dos microorganismos), a qual dura de 02 a 12 ou até 14 dias segundo alguns autores, e seu período de incubação varia entre 03 e 07 dias, sendo este período, compreendido como a primeira fase da doença não imune, apresentando sintomatologia branda e inespecífica. Após esta fase, ocorrerá o aparecimento de anticorpos específicos produzidos através do sistema imunológico, no qual as leptospiras irão se concentrar em alguns órgãos tais como rins, fígado e pulmão, além de musculatura esquelética onde, a partir deste momento, o animal irá apresentar a sintomatologia clássica da doença. Além da corrente sanguínea, esse agente pode também se multiplicar ativamente em outros líquidos orgânicos como linfa e líquor (FAINE et al., 1999; FAINE et al., 2000; ADLER; DE LA PEÑA MOCTEZUMA, 2010; SYKES et al., 2011).

Durante a fase de leptospiremia, o agente migra para os órgãos alvos que são rins e fígado, onde podem causar lesão aguda e insuficiência renal, além de comprometer os hepatócitos, no que resulta, eventualmente, em necrose aguda, fibrose hepática e hepatite ativa crônica (BIAZOTTI, 2006; GUIDI, 2006; SILVA, 2007).

Por volta de 14 semanas, existem indícios de que os equinos podem excretar leptospiras viáveis pela urina. Fato este que do ponto de vista epidemiológico os rins são a 
localização de maior importância nessa fase, uma vez que a urina se torna a principal via de eliminação das leptospiras, desta forma as leptospiras podem persistir por meses ou anos, tornando-se assim uma importante fonte de infecção para outros animais. Por ser considerada uma doença complexa e multifatorial, os animais podem adquirir a enfermidade através do contato direto, com a urina eliminada por qualquer animal que esteja infectado (FAINE et al., 2000).

Alguns trabalhos sugerem que as leptospiras usufruem da entrada da célula hospedeira e da rápida translocação como mecanismo para ocorrer á disseminação aos órgãos alvos e escaparem do sistema imune, uma vez que o lúmen dos túbulos renais é o local ideal para colonização desse agente. A doença aguda é caracterizada quando a infecção é instalada, porém quando há desenvolvimento da imunidade protetora e eliminação do agente, considerase o animal como portador crônico (FAINE et al., 2000; ATHANAZIO et al., 2008; KO et al., 2009).

Existem evidências que os animais de produção têm sido acometidos não só através da urina de animais infectados, mas também, através do sêmen e secreções vaginais, confirmando assim que a colonização das bactérias não são apenas encontradas nos túbulos renais, podendo aparecer também nos órgãos reprodutivos, além das glândulas anexas (ELLIS, 1994; LILENBAUM et al., 2009).

Segundo Pescador (2004), a placentite é caracterizada por trombose, vasculite e infiltração de células inflamatórias no estroma juntamente com hiperplasia adenomatosa cística e necrose do epitélio. Em estudo realizado por Sebastian et al (2005), foi identificado que as leptospiras são uma importante causa de abortamento e natimortalidade em equinos.

\section{Sinais clínicos}

De acordo com Braga et al (2011), os equinos podem apresentar uma variação de sintomatologia, porém geralmente se apresentam assintomáticos. Ellis et al (1983); Vasconcelos, (2000), relatam que os sinais clínicos variam de acordo com o sorovar envolvido, além do ambiente em que o animal é criado, todavia nos equídeos são observados com mais frequência alterações no sistema reprodutivo tais como abortamento, natimortalidade, infertilidades e parições de crias debilitadas.

Segundo Riet-Correa et al (2007), os abortamentos ocorrem após o terceiro mês de gestação, porém algumas vezes podem ocorrer após o sexto mês, mas na maioria das vezes os animais que abortam não apresentam sintomatologia clínica. 
Além de problemas reprodutivos, a enfermidade pode provocar uveíte recorrente, sendo esta uma complicação tardia, podendo levar o animal a apresentar, após meses e anos, sinais como hipópio, ceratite, fotofobia, conjuntivite e lacrimejamento podendo evoluir inclusive à cegueira. (RADOSTITIS, 2002; HARTSKEERL et al., 2004; BRAGA et al., 2010).

Segundo Radostitis et al., (2002), a reincidência da uveíte aguda, são separados por períodos sem sinais clínicos, porém nas fases iniciais ocorre a uveíte anterior e através das reincidências de episódios, lesam estruturas como cristalino, córnea, corpo vítreo, nervo óptico e retina.

Em trabalhos realizados por Donahue et al., (1991), foi demonstrado que existe uma relação entre o sv Pomona e a uveíte em animais infectados.

Girio e Lemos, (2007), relatam que determinadas svs de leptotospiras apresentam uma hemolisina que causa anemia, icterícia e hemoglobinúria, fato este que, após a leptospiremia, vai levar a um comprometimento do fígado, rins, pulmões, cérebro, adrenais, ovário, trompas e glândula mamária.

Os animais quando infectados com svs adaptados, geralmente se apresentam com a doença crônica e, algumas vezes, com características da doença subclínica em hospedeiros de manutenção, porém quando os svs, não são adaptados os mesmos irão causar doença aguda com sintomatologia grave. (HARTSKEERL et al., 2004; BRAGA et al., 2010).

\section{Diagnóstico}

Através de dados epidemiológicos e pela sintomatologia clínica, associando tais fatores aos testes laboratoriais, se pode chegar ao diagnóstico da leptospirose (DAHER et al., 2010).

Vários são os métodos laboratoriais disponíveis para diagnosticar a leptospirose, a exemplo da histopatologia, microscopia, cultivo, sorologia como os testes de aglutinação microscópica, aglutinação macroscópica, hemoaglutinação indireta, aglutinação microcapsular ou ELISA. (FAINE et al., 1999; AHMAD et al., 2005; THONGBOONKERD, 2008).

Os testes laboratoriais podem ser divididos em métodos de detecção direta e indireta. Pelos métodos diretos, pode-se lançar mão da microscopia de campo escuro, onde as leptospiras estarão presentes no sangue na fase aguda da doença, porém, quando apresenta-se negativa a esse teste, não significa que a doença não esteja presente. Esse mesmo teste pode ser realizado através de antígenos ou material genético em tecidos e fluídos corpóreos, tais 
como líquor e em geral, a urina, durante a fase de leptospirúria, entretanto, nesta fase só irá aparecer a partir do $15^{\circ}$ dia da doença. Quando encontrados em tecidos e suco gástrico de fetos abortados, pode-se observar a morfologia e motilidade da Leptospira spp. Já os métodos indiretos ou sorológicos são caracterizados pela detecção de anticorpos anti-Leptospira spp. (SANTA ROSA, 1970; LANGONI, 1996; FAINE et al., 1999).

De acordo com Levett (2001), a técnica da microscopia de campo escuro, algumas vezes pode gerar erros de interpretação e apresentar baixa sensibilidade.

Segundo Silva (2007), são necessários meios especiais para o cultivo da L. interrogans, de preferência meios que contenham soro, albumina ou meios sintéticos livres de proteínas. De acordo com Pospissil (2007), a cultura bacteriana pode ser realizada através de fluido fetal, fígado, leite, rins, conteúdo cérebro-espinhal, fluido peritoneal, urina ou até mesmo sangue.

A urina é considerada como material ideal para o cultivo bacteriano segundo Biazotti (2006), no entanto, é necessária a colheita de mais de uma amostra de urina, uma vez que, a liberação das leptospiras pela mesma é intermitente.

A fim de limitar o crescimento de outros microrganismos junto com a Leptospira, a seletividade dos meios de cultura para o desenvolvimento dessas bactérias é conferida pela adição de alguns antibióticos tais como: polimixina B, rifampicina, vancomicina, neomicina e 5-fluorouracil (BHART et al.,2003).

O meio Ellinghausen-McCullough-johnson-Harris (EMJH) é o mais utilizado para o cultivo, contendo assim ácido oléico, BSA como detoxificante e Tween 80 como fonte de carbono (ELLINGHAUSEN et al., 1965; JONSON et al., 1967) e os ácidos graxos de cadeia longa são sua principal fonte de energia (BASEMAN; COX, 1969).

O crescimento dessas bactérias é lento em cultivos iniciais, devendo ser avaliado até 13 a 26 semanas antes de serem descartadas, entretanto o crescimento das espécies saprófitas em meio de cultura pode variar de dois a 30 dias (FAINE et al., 2000).

Diante os métodos sorológicos existentes, o teste de SAM é o procedimento laboratorial mais difundido no diagnóstico da leptospirose, onde organismos vivos são utilizados como antígenos, utilizando cepas de referência no qual são identificadas através da reação de adsorção de aglutininas, onde títulos iguais ou maiores que 100 são considerados positivos (SANTA ROSA, 1970; FAINE et al., 1999, HUDSON, 2003), tal teste é baseado na composição dos lipopolissacarídeos de membrana e na reatividade de anticorpos presentes no soro dos pacientes no qual apresentam este antígeno (BHART et al., 2003). 
Quando diagnosticada precocemente, o tratamento da leptospirose deverá começar na fase de leptospiremia, ou seja, no início da doença, a fim, de prevenir uma infecção subclínica ou até problemas mais graves atingindo órgãos e sistemas, podendo levar o animal acometido à morte se não tratado a tempo (KOURY, 2006).

Apesar de ser possível fazer a identificação de svs e sorotipos de leptospiras através de sorologia, esses métodos demandam trabalho especializado e demorado, podendo ser substituído, sem prejuízos, pela técnica de Pulsed field Gel Electrophoresis (PFGE). Em alguns casos poderá ser necessária a realização de análise molecular (MACHRY et al., 2009).

Diante os métodos moleculares a Reação em Cadeia da Polimerase (PCR) é um teste que está sendo utilizado para detectar a presença da Leptospira em vários tecidos e fluidos corpóreos, podendo ampliar e selecionar sequências alvos de DNA através da utilização de primers LEP-1 e LEP-2 (DE SOUZA, 2011), esta técnica tem se mostrado eficiente por apresentar resultados em pouco tempo, além da boa sensibilidade nas amostras de sangue nas primeiras fases da doença (LEVETT et al., 2005), podendo ser detectados através da urina nas semanas posteriores em portadores crônicos, como também em amostras ambientais (SMYTHE et al., 2002; LEVETT et al., 2005; SYKES et al., 2011).

\section{Prevenção e controle}

A leptospirose, por se tratar de doença ocupacional e estar disseminada mundialmente, alguns cuidados devem ser tomados a fim de preveni-la. Já estão disponíveis algumas vacinas inativadas e que apresentam 12 sorovares distintos sendo eles: Hardjoprajitno, Canicola, Bratislava, Icterohaemorrhagiae, Copenhageni, Pomona, Grippothyphosa, Tarassovi, Andamana, Ballum, Wolffii e Pyrogenes destinadas aos equídeos, onde de acordo com o fabricante é recomendado aplicar dose e fazer um reforço após 30 dias para animais adultos nunca vacinados e jovens a partir de quatro meses de idade, onde o reforço tem que ser dado a cada 6 meses (DECHRA, 2020).

De acordo com Faine et al., (2000), o controle de infecções provocadas por leptospiras pode ser realizado de duas formas: uma que tem como objetivo erradicar por completo o agente no plantel, a qual é feita através da identificação e tratamento dos animais que se apresentarem positivos para a enfermidade ou aquelas que se propõe a controlar seus efeitos sobre os animais, sendo executadas através da vacinação e uso esporádico de antibióticos, porém, de acordo com Barthi et al (2003); Hartskeerl et al (2011); a erradicação completa da leptospirose é improvável, uma vez que não há uma implantação de medidas sanitárias adequadas, tendo em vista que seus principais reservatórios são os roedores, nos 
quais constituem a maior fonte de infecção por serem capazes de possuir os sorovares mais virulentos para as demais espécies.

Algumas medidas devem ser tomadas a fim de evitar a disseminação da enfermidade no rebanho. O conhecimento das fontes de infecção, vias de transmissão, controle sanitários, além de manejos adequados e monitoramento dos animais através de sorodiagnósticos são medidas de controle e prevenção da leptospirose (SABA JÚNIOR et al., 2008; LILENBAUM, 1998), sendo de suma importância para prevenir a doença, uma vez que através da identificação dos hospedeiros transmissores como, por exemplo, os roedores se pode aplicar medidas profiláticas, tais como saneamento adequado, evitando assim a presença do mesmo. No tocante a outras espécies que estejam positivas é importante chegar a um diagnóstico precoce do animal que está acometido a fim de realizar o tratamento do mesmo (BRASIL, 1995; FAINE et al., 1999; HARTSKEERL et al., 2011).

Troedsson (2003) relata que deve ser evitado a exposição de águas paradas para que os vetores em potencial não disseminem a leptospira, além disso deve ser realizado rotineiramente a desinfecção de boxes que tiveram contatos com animais positivos, o mesmo autor ainda cita que éguas que abortaram devem ser isoladas, os estábulos desinfectados e o produto do abortamento devidamente destinado.

\section{Tratamento}

Não existe um protocolo fixo para o tratamento da leptospirose em equinos. Segundo Sellnow (1999), existe um consenso entre clínicos e pesquisadores a respeito da utilização de antibióticos no tratamento da leptospirose, o mesmo autor sugere que seja feito tratamento com oxitetraciclina, estreptomicina ou penicilina por um período de uma semana. De acordo com Pavord e Pavord (2007) e Thomassian (2005), o tratamento da leptospirose equina deve ser realizado com antibióticos tais como estreptomicina, penicilina e tetraciclina, fato este que corrobora com a sugestão de tratamento do autor Sellnow (1999) citado anteriormente.

Faine et al. (2000), relata que o tratamento da leptospirose se baseia na utilização de antibióticos, além da terapia de suporte, embora segundo Guidugli et al (2000),existem controvérsia do benefício da antibioticoterapia na diminuição da letalidade associada à doença grave.

De acordo com Radostits et al (2002), em animais que apresentam sintomatologia ocular, ou seja, uveíte recorrente, provocada por leptospirose, é realizado a terapia sintomática através da utilização de antiinflamatórios esteróides e não esteróides e midriáticos, sendo o 
Flunixin meglumine o anti-inflamatório não esteroidal de escolha. Com relação aos antiinflamatórios esteroidais são utilizados de 3 a 4 vezes por dia, topicamente no olho afetado, também são utilizados antibióticos tópicos como, por exemplo, à base de neomicina, polimixina B ou gentamicina, auxiliando assim na prevenção de infecções oportunistas, além desses medicamentos também é utilizada antibioticoterapia parenteral, a fim, de reduzir os títulos das Leptospiras spp., porém não se indica terapia em olhos não doloridos com lesões de uveíte crônica em estágio final.

Vasconcellos (1997), relata que do ponto de vista preventivo, uma das formas de evitar a enfermidade é através da utilização racional de antibióticos que bloqueiem a eliminação de leptospiras através da urina, sêmen e corrimento vaginal, o mesmo autor relata ainda que o medicamento de escolha nesses casos é a estreptomicina, devendo ser aplicada por via parenteral em uma concentração de $25 \mathrm{mg} / \mathrm{Kg}$ de peso vivo. Porém, Radostits (2002) menciona a possibilidade de tratar animais infectados, por sv de manutenção com diidroestreptomicina $\mathrm{G}$ com concentração de $25 \mathrm{mg} / \mathrm{Kg}$ por um período de um, três ou cinco dias. De acordo com Vasconcellos (1997), as possibilidades de tratamento precisam ser revistas, sugerindo assim a inclusão do emprego integrado de tratamento com a imunização.

Éguas que abortaram por leptospirose, de acordo com Troedsson (1997), seu tratamento deve ser realizado através da utilização de estreptomicina, penicilina ou oxitetraciclina por um período de uma semana, todavia de acordo com Radostitis (2002), esses animais devem ser isolados e ter as baias desinfetadas, além da necessidade de se realizar o tratamento com antibioticoterapia sistêmica como estreptomicina $10 \mathrm{mg} / \mathrm{Kg}$ duas vezes ao dia, penicilina benzatina $15000 \mathrm{UI} / \mathrm{Kg}$ duas vezes ao dia ou oxitetraciclinas 10 $\mathrm{mg} / \mathrm{Kg}$ por uma semana.

Sellnow (1997) relata que existem estudos mostrando que éguas no final da gestação, tratadas com penicilina $\mathrm{G}$ potássica que apresentavam altos títulos para leptospirose pariram potros normais.

\section{CONSIDERAÇÕES FINAIS}

Diante dessa revisão bibliográfica, foi possível perceber que a presença de diferentes svs de leptospira infectando a espécie equídea está relacionada com a região onde estes animais vivem. Contudo, mesmo havendo svs de predileção para este hospedeiro, existe a possibilidade de aumentar a quantidade de Leptospiras spp. adaptadas ao mesmo a partir do 
contato de equídeos com diferentes reservatórios, hospedeiros ou pela convivência em ambiente de risco.

No tocante ao diagnóstico é preciso que a aplicação de testes se torne uma prática rotineira, a fim de detectar a leptospira nos rebanhos de equídeos no Brasil, uma vez que em sua maioria esses animais encontram-se assintomáticos.

Aspectos relacionados às medidas de controle e prevenção devem ser aplicados devidamente com vistas a proporcionar um ambiente seguro, evitando a introdução e disseminação da doença num rebanho, o que representa fator de risco para animais e humanos, além de causar perdas significativas, afetando a economia e, consequentemente a cadeia produtiva de equídeos.

\section{REFERÊNCIAS}

ABUCHAIM, D.M. Presença de aglutininas anti-Leptospira em soro de equinos no Estado do Rio Grande do Sul. Arquivo da Faculdade de Veterinária UFRGS, v. 19, n. 1 p. 9-14, 1991.

ADLER, B.; DE LA PEÑA MOCTEZUMA, A. Leptospira and leptospirosis. Veterinary microbiology, v. 140, n. 3-4, p. 287-296, 2010.

AHMAD, S. N.; SHAH, S.; AHMAD, F. M. Laboratory diagnosis of leptospiroses. Journal of Postgrad in Medicine, v. 51, n. 3, p. 195-200, 2005.

AMORIM M.C.; FERREIRA, R. Doença de Weil ou leptospirose. 2009. Disponível em: http://tudolevaapericia.blogspot.com.br/2009/08/doenca-de-weil-ou-leptospirose.html. Acesso em: 10 fev. 2013.

ARAÚJO, I.G.R.; LANGONI, H.; GUERRA, P.C.; MENDONÇA, A.O. Pesquisa de aglutininas antileptospíricas em soro sanguíneo de asininos de veículos de tração animal na cidade de São Luis do Maranhão. Pesquisa em Foco, v. 9, n. 13, p. 141-149, 2001.

ARAÚJO, V.E.M.; MOREIRA, E.C.; SILVA, J.A.; CONTRERAS, R.L. Freqüência de aglutininas anti-Leptospira interrogans em soros sangüíneos de bovinos, em Minas Gerais, de 
1980 a 2002. Arquivos Brasileiros em Medicina Veterinária e Zootecnia, v. 57, n. 4, p. 430-435, 2005.

ATHANAZIO, D.A.; SILVA, E.F.; SANTO, C.S.; ROCHA, G.M.; VANNIERSANTOS, M. A.; MCBRIDE, A.J.; KO, A.I.; REIS, M.G. Rattus norvegicus as a model for persistent renal colonization by pathogenic Leptospira interrogans. Acta Tropica, v. 105, n. 2, p. 176-180, 2008 .

BARCELlOS, C.; LAMMERHIRT, C.B.; ALMEIDA, M.A.B.; SANTOS, E. Distribuição espacial da leptospirose no Rio Grande do Sul, Brasil: recuperando a ecologia dos estudos ecológicos. Cadernos Saúde Pública, v. 19, n. 5, p. 1283- 1292, 2003.

BARWICK, R.S.; MOHAMMED, H.O.; MCDONOUGH, P.L.; WHITE, M.E. Risk factors associated with the likelihood of Leptospiral seropositivity in horses in the state of New York. American Journal of Veterinary Research, v. 58, n. 10, p. 1097-1103, 1997.

BASEMAN, J.B.; COX, C.D. Intermediate energy metabolism of Leptospira. Journal of Bacteriology, v. 97, n. 3, p. 992-1000, 1969.

BEER, J. Leptospirose In: BEER, J. Doenças Infecciosas em Animais Domésticos. v. 2. São Paulo: Roca, p. 305-313, 1988.

BHARTI, A.R; NALLY, J.E.; RICALDI, J.N.; MATTHIAS M.A.; DIAZ, M.M.; LOVETT M.A.; LEVETT, P.N.; GILMAN, R.H.; WILLIG, M.R.; GOTUZZO, E.; VINETZ, J.M. Leptospirosis: a zoonotic disease of global importance. The Lancet Infection Desease, v. 3, n. 12 p. $757-71,2003$.

BIAZOTTI, R. Leptospirose Canina. Trabalho de conclusão de curso (pós-graduação "Lato Sensu em clínica médica de pequenos animais) - Universidade Castelo Branco. Rio de Janeiro, 2006.

BLENDEN, D.C. Aspectos epidemiológicos de la leptospirosis. In: $8^{\mathrm{a}}$ Reunion Interamericana sobre el Controle de la Fiebre Aftosa y otras Zoonosis, Guatemala, 1975. 
Publicacion Científica 316, Organizacion Panamericana de La Salud, Washington, p. 160$168,1976$.

BRAGA, J.; HAMOND, C.; MARTINS, G.; ABREU, R.N.; LILENBAUM, W. Ophtalmic alterations in horses with leptospirosis by serovar Icterohaemorrhagiae in Rio de Janeiro, Brazil. Pesquisa Veterinária Brasileira, v. 31, n. 2, p. 147-150, 2011.

BRAGA, J.; HAMOND, C.; MARTINS, G.; LILENBAUM, W. Detection of anti-Leptospira antibodies in aqueous humor of horses with naturally occurring uveitis. Online Journal of Veterinary Research, v. 14, n. 2, p. 212-217, 2010.

BRASIL. Ministério da Saúde. Manual de Leptospirose. Brasília: Fundação Nacional de Saúde. 1995.

CHIARELI, D.; MOREIRA， E.C.; GUTIÉRREZ， H.O.D; RODRIGUES， R.O.; MARCELINO, A.P.; MENESES, J.N.C; ALMEIDA, V.M.A. Freqüência de aglutininas antiLeptospira interrogans em eqüídeos, em Minas Gerais, 2003 a 2004. Arquivo Brasileiro de Medicina Veterinária e Zootecnia, v. 60, n. 6, p. 1576-1579, 2008.

CORRÊA, M.O.A.; AMATO NETO, V.; VERONESI, R.; FABBRI, O.S. Leptospiroses em eqüinos: Inquérito sorológico. Revista do Instituto Adolfo Lutz, v. 15, n. único, p. 186-193, 1957.

DAHER, E. F.; ABREU, K. L. S.; SILVA JUNIOR, G. B. Leptospirosis-associated acute kidney injury. Journal of Brazilian Nefrology, v. 4, n. 43, p. 400-407, 2010.

DE SOUZA, V.R. Leptospirose: aspectos epidemiológicos, clínicos e laboratoriais. Trabalho de conclusão de curso (Pós-graduação em Análises Clínicas e Gestão de Laboratório) Universidade Vale do Rio Doce, Minas Gerais, 2011.

DECHRA. Lepto equus. Disponível em: https://www.dechra.com.br. Acesso em: 5 ago. 2020. 
DOMINGUES, P.F.; LANGONI, H. Manejo sanitário animal. 1. ed. Rio de Janeiro: EPUB. 2001.

DONAHUE J.M.; SMITH B.J.; REDMON K.J.; DONAHUE J.K. Diagnosis and prevalence of leptospira infection in aborted and stillborn horses. Journal of Veterinary Diagnostic Investigation, v. 3, n. 2, p. 148-151, 1991.

DOS SANTOS, C.S.; GUEDES JÚNIOR D.S.; PEREIRA R.C.G.; SANTOS C.C.A.; CASTRO, V.E; JESUS, V.L.T. Inquérito sorológico da ocorrência de leptospirose em equídeos da microrregião de Itaguaí no estado do Rio de Janeiro-RJ. Revista Brasileira de Medicina Veterinária, v. 34, n. 2, p. 96-100, 2012.

ELlinghaUSEN HC, Jr.; MCCULlOUGH W.G. Nutrition of Leptospira Pomona and Growth of Other Serotypes: fractionation of Oleic Albumin Complex and a Medium OF Bovine Albumin and Polysorbate 80. American Journal of Veterinary Research, v. 26, n. 1, p. 45-51, 1965.

ELLIS, W.A. Leptospirosis as a cause of reproductive failure. In: MILLER, R.B. The Veterinary Clinics of North America: Food Animal Pratice, Philadelphia, v. 10, n. 3, p. 463-476, 1994.

ELLIS, W.A.; O'BRIEN, J.J.; CASSELLS, J. Role of cattle in the maintenance of Leptospira interrogans serotype hardjo infection in North Ireland. Veterinary Record, v. 108, n. 26, p. 555-557, 1981.

ELLIS, W.A., O'BRIEN, J.J., CASSELS, J.A., MONTGOMERY, J. Leptospiral infection in horses in Northern Ireland: Serological and microbiological findings. Equine Veterinary Journal, v. 15, n. 4, p. 317-320, 1983.

FAINE, S.; ADLER, B.; BOLIN, C.; PEROLAT, P. Leptospira and leptospirosis. 2. ed. Australia: Medical Science. 1999. 
FARIAS, A. Manual de leptospirose. 4. ed. Brasília: Ministério da Saúde. Fundação Nacional de Saúde, 1999.

FREITAS, D.C.; GOMES, C.E.S.; LACERDA, J.P.G.; LIMA, F.P. Notas sobre leptospirose equina. Arquivo do Instituto de Biologia, v. 27, p. 93-96, 1960.

GILGER, B.C. Equine Recurrent uveits. In: ROBINSON, N. E. Current terapy in equine medicine. Missori: Sauders, p. 468-472, 2003.

GIRIO R.J.S.; LEMOS R.A.A. Doenças Bacterianas, Leptospirose In: RIET-CORREA F. Doenças de Ruminantes e Eqüídeos. Santa Maria, RS: Palotti, v. 1, n. 3, p. 331-352, 2007.

GOMES, A.H.B.; OLIVEIRA, F.C.S.; CAVALCANTI, L.A.; CONCEIÇÃO, I.R.; SANTOS, G.R.; RAMALHO, E.J.; VIEGAS, S.A.R.A. Ocorrência de aglutininas anti-Leptospira em soro de eqüinos no estado da Bahia. Revista Brasileira de Saúde e Produção Animal, v. 8, n. 3, p. 144-151, 2007.

GUIDUGLI, F. Prevenção e tratamento da leptospirose: Revisão sistemática de ensaios clínicos aleatorizados com análises. Universidade Federal de São Paulo. 2006.

GUIDUGLI, F., CASTRO, A.A.; ATALLAH, A.N. Antibiotics for preventing leptospirosis. Cochrane Database Systematic Reviews, 2000.

HARTSKEERL, R.A.; COLLARES-PEREIRA, M.; ELLIS, W.A. Emergence, control and reemerging leptospirosis: dynamics of infection in the changing world. Clinical Microbiology and Infeccion, v. 17, n. 4, p. 494-501, 2011.

HARTSKEERL, R.A., GORIS, M.G.A., BREM, S., MEYER, P., KOPP, H., GERHARDH, S; WOLLANKE, B. Classification of Leptospira from the eyes of horses suffering from recurrent uveitis. Journal of Veterinary Medicine B, v. 51, n. 3, p. 110-115, 2004.

HONG, C.B.; DONAHUE, J.M.; GILES, R.C.; PETRITES-MURPHY, M.B.; POONACHA, K.B.; ROBERTS, A.W.; SMITH, B.J.; TRAMONTIN, R.R.; TUTTLE PA; SWERCZEK 
TW. Equine abortion and stillbirth in central Kentucky during 1988 and 1989 following seasons. Journal of Veterinary Diagnostic Investigation, v. 5, n. 4, p. 560-566, 1993.

HUDSON, D.B. Leptospirosis of domestic animals. 2003. Disponível em: http:www.ianr.uml.edu/pubs/animalisease/g417.htm. Acessado em: 18 jul. 2003.

JARDIM, E.C.; SILVA, R.L.; ALMEIDA, M.N.R.; FICHTNER, S.S.; CANDIDA, M.F. Aglutininas antileptospira em equinos no Estado de Goiás. Anais da Escola de Agronomia e Veterinária da UFG, v. 8, n. 1, p. 142-149, 1978.

JOHNSON, R.C.; HARRIS, V.G. Differentiation of pathogenic and saprophytic leptospires. Journal of Bacteriology, v. 94, n. 1, p. 27-31, 1967.

KINDE H.; HIETALA S.K.; BOLIN C.A.; DOWE J.T. Leptospiral abortion in horses following a flooding incident. Equine Veterinary Journal, v. 28, n. 4, p. 327-330, 1996.

KO, A.I.; GOARANT, C.; PICARDEAU, M. Leptospira: the dawn of the molecular genetics era for an emerging zoonotic pathogen. Nature Reviews Microbiology, v.7, n.10, p.736-747. 2009.

KOURY, M.C; SILVA, V. Epidemiologia e Controle da Leptospirose Humana nas Regionais do município de Belo Horizonte, Minas Gerais. Centro Universitário Metodista, Belo Horizonte. 2006.

LANGONI, H. Introdução as Zoonoses. Apostila da Disciplina de Zoonoses da UNESPBotucatu. São Paulo. 1996.

LANGONI, H.; DA SILVA, A.V.; PEZERICO, S.B.; DE LIMA, V.Y.J. Anti-Leptospira agglutinins in equine sera, from São Paulo, Goiás, and Mato Grosso do Sul, Brazil, 19962001. Journal of Venomous Animals and Toxins including Tropical Diseases, v.10, n.3, p.207-218, 2004. 
LEES, W.V.; GALE, P.S.; Titers to Leptospira species in horses in Alberta. Canadian Veterinary Journal, v.35, n.10, p.636-640, 1994.

LEVETT, P.N. Leptospirosis. Clinical Microbiology Reviews, v.14, n.2, p.296-326, 2001.

LEVETT, P.N.; MOREY, R.E.; GALLOWAY, R.L.; TURNER, D.E.; STEIGERWALT, A.G.; MAYER, L.W. Detection of pathogenic leptospires by realtime PCR. Journal of Medical Microbiology, v. 54, p. 45-49, 2005.

LILENBAUM, W. Leptospirosis on animal reproduction: IV. Serological findings in mares from six farms in Rio de Janeiro, Brazil (1993-1998). Brazilian Journal of Veterinary Research and Animal Science, v. 35, n. 2, p. 61-63, 1998.

LILENBAUM, W; VARGES, R; RISTOW, P.C.L.V.B; CORTEZ, A; SOUZA, S.O; RICHTZENHAIN, L; VASCONCELLOS, S.A. Identification of Leptospira spp. carriers among seroreactive goats and sheep by Polymerase Chain Reaction. Research in Veterinary Science, v. 87, n. 1, p. 16-19, 2009.

LINHARES, G.F.C.; GIRIO, R.J.S.; LINHARES, D.C.L.; MONDEIRO, L.C.; DE OLIVEIRA, A.P.A. Sorovares de Leptospira interrogans e respectivas prevalências em cavalos da microrregião de Goiânia, GO. Ciência Animal Brasileira, v. 6, n. 4, p. 255-259, 2005

MACHRY, L.; RIBEIRO, R.L.; VITALBRAZIL, J.M.; RAMOS, T.M.V.R; BALASSIANO, I.T.; PEREIRA, M.M. Caracterização fenotípica e genotípica de Cepas de Leptospira spp. isoladas de um surto de leptospirose no estado no acre em 2005-2006. In: $25^{\circ}$ Congresso Brasileiro de Microbiologia. Anais eletrônicos... Pernambuco, 2009. Disponível em: https://www.sbmicrobiologia.org.br/25cbm-anais/resumos/R1490-1.html. Acesso em: 11 ago. 2020.

MAPA. Revisão do estudo do complexo do agronegócio do cavalo. Ministério da Agricultura Pecuária e Abastecimento. Disponível em: https://www.gov.br/agricultura. Acesso em: 29 jul. 2020. 
MELO, L.S.S.; DE CASTROL, M.B.; LEITE, R.C.; MOREIRA, E.C.; DE MELOL, C.B. Principais Aspectos da Infecção por leptospiras em Ovinos. Ciência Rural, v. 40, n. 5, p. 1235-1241, 2010.

MOLNAR, E.; DIAS, H.L.T.; MOLNAR, L. Estudo comparativo entre o teste da soroaglutinação microscópica $(\mathrm{SAM})$ e o imunoensaio ligado à enzima (ELISA) para o diagnóstico da leptospirose equina. Revista Brasileira de Medicina Veterinária, v. 23, n. 4, p. $151-155,2001$.

PARMA, A.E.; SANZ, M.E.; LUCCHESI, P.M.; MAZZONELI, J.; PETRUCCELLI M.A. Detection of an antigenic protein of Leptospira interrogans which shares epitopes with the equine córnea and lens. The Veterinary Journal, v. 153, n. 1, p. 75-79, 1997.

PAVORD, T.; PAVORD, M. The Complete Equine Veterinary Manual. 2. ed. United Kingdom: David and Charles. 2007.

PELlEGRIN, A.O; SILVA, R.A.M.S; RIBEIRO, S.C. Ocorrência de aglutininas antiLeptospira em eqüinos do Pantanal Mato-Grossense, sub-região da Nhecolândia. In: Congresso Brasileiro de Medicina Veterinária. Anais... Olinda: SPEMV, p. 190, 1994.

PEREIRA, J.A. Soroprevalência da infecção por Leptospira spp. em matrizes suínas oriundas do médio norte do estado de Mato Grosso, Brasil. Dissertação (Mestrado em Ciências Veterinárias) - Faculdade de Agronomia, Medicina Veterinária e Zootecnia, Universidade Federal de Mato Grosso, Cuiabá. 2009.

PESCADOR, C.A.; CORBELlinI, L.G.; LORETTI, A.P.; WUNDER JUNIOR, E.; FRANTZ, F.J.; DRIEMEIER, D. Aborto equino por Leptospira sp. Ciência Rural, v. 34, n. 1, p. 271-274, 2004.

PICARDEAU, M.; BULACH, D.M.; BOUCHIER, C.; ZUERNER, R.L.; ZIDANE, N.; WILSON, P.J.; CRENO, S.; KUCZEK, E.S.; BOMMEZZADRI, S.; DAVIS, J.C.; MCGRATH, A.; JOHNSON, M.J.; BOURSAUX-EUDE, C.; SEEMANN, T.; ROUY, Z.; 
COPPEL, R.L.; ROOD, J.I.; LAJUS, A.; DAVIES, J.K.; MÉDIGUE, C.; ADLER, B. Genome sequence of the saprophyte Leptospira biflexa provides insights into the evolution of Leptospira and the pathogenesis ofleptospirosis. PLoS One, v. 3, n. 2, 9p., 2008.

PINNA, M.H., VARGES, R., ABREU, R., LILENBAUM, W. Outbreak of equine leptospirosis by s. Bratislava. Online Journal of Veterinary Research, v. 11, n. 3, p. 1-4, 2007.

PIRES NETO, J.A.S.; HESSE, F.; OLIVEIRA, M.A.M. Leptospirose equina: aspectos clínicos, tratamento, prevenção e levantamento sorológico. Veterinária em Foco, v. 2, n. 2 p.165-176, 2005.

POSPISSIL, T.T.F. Leptospirose Equina. Monografia (Especialista Latu Sensu) -Faculdade de Jaguariuna. São Paulo, 36p. 2007.

QUINN, P.J.; CARTER, M.E.; MARKEY, B.; CARTER G.R. Clinical Veterinary Microbiology. 1. ed. Spain: Grafos, p. 292-303, 1994.

QUINN P.J., MARKEY B.K., CARTER M.E., DONELlY W.J., LEONARD F.C. Microbiologia veterinária e doenças infecciosas. trad. Lúcia Helena Niederauer Weiss e Rita Denise Niederauer Weiss. Porto Alegre: ARTMED, 2005.

RADOSTITS, O.M.; GAY, C.C.; BLOOD, D.C.; HINCHCLIFF, K.W. Um tratado de doenças dos bovinos, ovinos, suínos, caprinos e equinos. 9. ed. Rio de Janeiro, p. 874-887, 2002.

RADOSTITS, O.M.; GAY, C.C.; HINCHCLIFF, K.W.; CONSTABLE, P.D.; DONE, S. H.; JACOBS, D.E.; IKEDE，B.O.; MCKENZIE，R.A.; COLWELL，D.; OSWEILER，G.; BILDFELL, R.J. Veterinary medicine. A textbook of the diseases of cattle, sheep, pigs, goats and horses. 9. ed. London: W.B. Saunders, 2000.

RIET-CORREA F.; SCHILD, A.L.; LEMOS, R.A.A.; BORGES, J.R.J. Doenças de Ruminantes e eqüídeos. 3. ed. Rio Grande do Sul: Gráfica editorial Palotti, v. 1. 2007. 
ROMERO, E.C. Search for agglutinating antibody to Leptospira and Letonema in horses, São Paulo, Brazil. Brazilian Journal of Veterinary Research and Animal Science, v. 31, n. 3, p. 210-215, 1994.

SABA JÚNIOR, P.; VIU, M.A.O.; FERRAZ, H.T. Etiopatogenia, diagnóstico e controle da leptospirose em animais de produção. Pubvet, v. 2, n. 11, 2008.

SANTA ROSA, C.A. Diagnóstico laboratorial das leptospiroses. Revista de Microbiologia, v.1, n. 2, p. 97-109, 1970.

SANTANA, L.A.S. Alterações Espermáticas e dos Níveis Plasmáticos de Testosterona em Cães Experimentalmente Infectados por LeptospirasInterrogans Sorovar Canina. Dissertação (Mestre em Medicina Veterinária) - Faculdade de Ciências Agrária e Veterinárias, Universidade Estadual Paulista. São Paulo, 57p. 2008.

SCHMIDT, V.; AROSI, A.; SANTOS, A.R. Levantamento sorológico da leptospirose em caprinos leiteiros no Rio Grande do Sul, Brasil. Ciência Rural, v. 32, n. 4, p. 609-612, 2002.

SEBASTIAN, M.; GILES, R.; ROBERTS, J.; POONACHA, K.; HARRISON, L.; DONAHUE, J.; BENIRSCHKE, K. Funisitis associated with leptospiral abortion in an equine placenta. Veterinary Pathology, v. 42, n. 5, p. 659-662, 2005.

SELLNOW, L. Leptospirose: mal de muitas faces. Revista Horse Business, ed. 56, São Paulo, 1999.

SILVA, L.G. Leptospirose Canina. Monografia (Especialista em Clínica Médica e cirurgia de pequenos animais) - Universidade Castelo Branco. Rio de Janeiro, 2007.

SMYTHE, L.D.; SMITH, I.L.; SMITH, G.A.; DOHNT, M.F.; SYMONDS, M.L.; BARNETT, L.J; MACKAY, D.B. A quantitative PCR (TaqMan) assay for pathogenic Leptospira spp. BMC Infectious Diseases. v. 2, n. 13, p. 1-7, 2002. 
SYKES, J.E.; HARTMANN, K.; LUNN, K.F.; MOORE, G.E.; STODDAR, R.A.; GOLDSTEIN, R.E. 2010 ACVIM Small Animal Consensus Statement on Leptospirosis: diagnosis, epidemiology, treatment, and prevention. Journal of Veterinary Intern Medice, v. 25, n. 1, p. 1-13, 2011.

THOMASSIAN, A. Enfermidades Infecciosas. In: Enfermidades dos Cavalos. 4. Ed. São Paulo: Livrarias Varela. 2005.

THONGBOONKERD, V. Proteomics in lepitospirosis research: towards molecular diagnostics and vaccine development. Expert Review of Molecular Diagnostics, v. 8, n. 1, p. 53-61, 2008.

TROEDSSON, M.H.T. Abortion. In: ROBINSON, N.E. Current Therapy in Equine Medicine. New York: Saunders, p. 534-540, 1997.

TROEDSSON, M.H.T. Placentitis. In: ROBINSON, N.E. Current Therapy in Equine Medicine. Philadelphia: WB Daunders, p. 297-300, 2003.

VASCONCELLOS, S.A. Leptospirose em animais domésticos e silvestres - prevenção e controle. In: Oficina Estado da Arte e Prioridades para P\&D em Leptospirose. Anais... Rio de Janeiro: FIOCRUZ, 12 p. 2000.

VERONESI, R. Doenças Infecciosas e Parasitárias. 8. ed. Rio de Janeiro: Guanabara Koogan, p. 565-579, 1991.

YAN, W.; FAISAL, S.M.; DIVERS, T.; McDONOUGH, S.P.; AKEY, B.; CHANG, Y.F. Experimental Leptospira interrogans serovar Kennewicki infection of horses. Journal of Veterinary Internal Medicine, Lawrence, v. 24, n. 4, p. 912-917, 2010. 